\title{
Environmental factors of diarrhea prevalence among under five children in rural area of North Gondar zone, Ethiopia
}

\author{
Atalay Getachew ${ }^{1}$, Alebachew Tadie ${ }^{2 *}$, Mulat G.Hiwot ${ }^{1}$, Tadesse Guadu', Daniel Haile ${ }^{1}$, Teklay G.Cherkos ${ }^{3}$, \\ Zemichael Gizaw ${ }^{1}$ and Marta Alemayehu ${ }^{3}$
}

\begin{abstract}
Background: In the sub-Saharan countries, many of the children including found in health facilities are not having sufficient care of diarrhea. Diarrheal disease in these countries is one of the main causes of deaths for under-five children.

Methods: A community-based cross-sectional study design was used to collect data from May-June, 2016 to determine environmental factors of diarrhea prevalence among under five children in North Gondar Zone. Structured interview questionnaire and observational checklist were used to collect data. Using probability proportion to size, number of households was determined in each district. The multivariable binary logistic regression analysis with a $95 \%$ confidence interval and $p<0.05$.was used to identify environmental factors associated with childhood diarrheal disease.
\end{abstract}

Results: Of the total 736 individuals surveyed from 736 households, a total of 163 (22.1\%) with [95\% Cl (19.1-25. 1)] under -five children had 2 week period diarrhea prevalence. Roof material [AOR: 1.99, 95\% Cl (1.1-3.82)], hand washing facility [AOR: $0.52,95 \% \mathrm{Cl}(0.33-0.82)]$, presence of Latrine facility [AOR: 1.65, 95\% Cl (1.01-2.72)], presence of feces around the pit hole [AOR: 1.65, 95\% Cl (1.01-2.72)], presence of feces around the house compound [AOR: $1.65,95 \% \mathrm{Cl}(1.01-2.72)]$ and risk of contamination of household storage had significant associations with diarrheal morbidity.

Conclusion: The prevalence of childhood diarrheal disease among under - five children in rural settings of northwest Ethiopia was high. Type of roof material, hand washing facility, presence of Latrine facility, presence of feces around the pit hole, presence of feces around the house compound and risk of contamination of household storage had significant associations with diarrheal morbidity.

Keywords: Diarrhea, Environmental factors, Under-five children, North Gondar zone

\section{Background}

In the sub-Saharan countries, many of the children including found in health facilities are not having sufficient care of diarrhea. Diarrheal disease in these countries is one of the main causes of deaths for under-five children [1]. One child passed away from the world within each $15 \mathrm{~s}$ due to diarrheal disease [2]. Moreover, in the developing countries alone about two millions of people most

\footnotetext{
*Correspondence: alietadie@gmail.com

${ }^{2}$ Department of Ecological and Systematic Zoology, College of Natural and

Computational Science, University of Gondar, Gondar, Ethiopia

Full list of author information is available at the end of the article
}

of which are under five children die annually [3]. Therefore, there should be an increased work at health care facilities and among the community for the childhood diarrhea care quality [1].

Many factors are responsible for the diarrheal disease. They are socio-economic $[4,5]$, behavioural like breastfeeding $[6,7]$ and environmental factors such as water, sanitation and waste disposal mechanism [8-11]. Different studies have been conducted in different parts of Ethiopia on diarrhea prevalence and reported 12.2, 35.6, $22.5,9.9$, and $28.9 \%$ [6-10], respectively.

(c) The Author(s). 2018 Open Access This article is distributed under the terms of the Creative Commons Attribution 4.0 International License (http://creativecommons.org/licenses/by/4.0/), which permits unrestricted use, distribution, and reproduction in any medium, provided you give appropriate credit to the original author(s) and the source, provide a link to the Creative Commons license, and indicate if changes were made. The Creative Commons Public Domain Dedication waiver (http://creativecommons.org/publicdomain/zero/1.0/) applies to the data made available in this article, unless otherwise stated. 
Environmental factors like the type of water source, presence of sanitation facilities, solid waste disposal system and floor type in the kitchen are found to be crucial contributors for the high prevalence of diarrheal diseases. Particularly, diarrhea occurrence is more associated with unsafe/unprotected water sources e.g. ponds, wells, rivers, lakes [12]. Other more environmental health risk factors of childhood diarrhea include improved sanitation, hand washing facilities, poor knowledge on diarrheal cases, and improved latrine $[8,11]$. Therefore, the current study was designed to determine the prevalence of diarrheal disease in under five children and assess the associated environmental factors in the rural areas of North Gondar zone, Ethiopia.

\section{Method}

\section{Study area}

A community-based cross-sectional study was conducted in North Gondar Zone from April to June 2016. Gondar town is located $739 \mathrm{~km}$ far from Addis Ababa to the Northwest of Ethiopia and $180 \mathrm{~km}$ in the north direction of Bahir Dar (Capital of Amhara Region). North Gondar is one of the eleven zones in Amhara Regional State having 22 administrative districts. As the data gained from North Gondar Zonal Health Department, the total projected population of North Gondar Zone in $2015 / 16$ is $3,704,740$. The majority of which $2,920,007$ $(78.8 \%)$ populations reside in rural areas whereas the rest 784,733 (21.2\%) are in urban areas.

\section{Study design and period}

A community based cross-sectional study design was used to collect data from May-June 2016.

\section{Sample size determination and sampling procedures}

Epi info version 3.5.3 was used to calculate the sample size based on an assumption that $18 \%$ of the under-five children had two-week prevalence of diarrhea in North Gondar (26) with marginal error of $4 \%$, a standard score corresponding to $95 \%$ certainty, design effect of 2 , accounted for two-stage sampling and none response rate $5 \%$. The total sample size that was included in the study is 743 households that should have at least one under-five child. From randomly selected four districts (Dembia, Gondar Zuriya, Chilga, and Sanja) of the 22 total districts of North Gondar Zone, multi-staged sampling procedure was employed.

Using probability proportional (PPS) to size, the number of households was determined in each district. Then, $25 \%$ of total kebeles was selected from each district by simple random sampling technique and systematic sampling technique was applied to select study households. In case, where there are more than one under-five children in the same household, index child was selected by lottery method to collect information on child's health characteristics. The first household interview was identified by a modified random walk method and if there is no mother/care taker or under five child in the selected household, the next nearest household was included in the survey.

\section{Data collection methods and tools}

The data were collected by using face to face interview with pretested structured questionnaires and observational checklists which were prepared in English and translated to the local language, Amharic. To improve the quality of data collection, two-day training was given to 16 data collectors and 8 supervisors about way of interview, the nature of questionnaires, rechecking of filled questionnaires and approaches to household heads.

\section{Data analysis}

All data collection forms were checked for completeness and reliability before entry into software. Data entry and cleaning were done using Epi info version 3.5.3 computer software. Data were analyzed by using SPSS ver.20. Descriptive analyses were deployed for both dependents and independent variables. The frequency distribution of both dependent and independent variables were worked out. Logistic regression analysis was used to see the relationship of selected variables to diarrheal disease. Eight variables with $P$ - value less than 0.2 in bivariate analysis were included in the multivariate logistic regression. Finally, data were presented in the form of tables and figures.

\section{Ethical considerations}

Ethical clearance was obtained from the Institutional Ethical Committee of the University of Gondar. Moreover, the consent of participants was obtained from the respective district health offices. The confidentiality of information was maintained during and after an interview in which coding was used for all the data collected. Participants in the study had given verbal consent.

\section{Results \\ Socio-demographic characteristics of the study participants}

In this study, a total of 736 respondents of households participated whose mean $( \pm$ SD) age was $30 \pm 7$ years nearly half, $362(49.2 \%)$ respondents were aged between 25 and 34 year. The majority, 690 (93.8\%) of participants religion were orthodox and more than half of the respondents 431 (58.5\%) were unable to read. Most of the respondents 693 (94.2\%) were married and housewives $632(85.8 \%)$. Majority, 463(62.9\%) of the respondents had a family size less than five individuals and 423 $(57.3 \%)$ of the respondent had income less than 1000 ETB (Table 1). 
Table 1 Socio-demographic characteristics of the study participants in North Gondar Zone, June, 2016 ( N = 736)

\begin{tabular}{|c|c|c|}
\hline Variables & Number & Percent (\%) \\
\hline \multicolumn{3}{|l|}{$\overline{\text { Age }}$} \\
\hline$<15$ & 3 & 0.4 \\
\hline $15-24$ & 149 & 20.2 \\
\hline $25-34$ & 362 & 49.2 \\
\hline$>35$ & 222 & 30.2 \\
\hline \multicolumn{3}{|l|}{ Religion of parents } \\
\hline Orthodox & 690 & 93.8 \\
\hline Protestant & 6 & 0.8 \\
\hline Muslim & 40 & 5.4 \\
\hline \multicolumn{3}{|l|}{ Educational level } \\
\hline Unable to read and write & 431 & 58.6 \\
\hline Read and write & 62 & 8.4 \\
\hline $1-8$ & 135 & 18.3 \\
\hline $9-12$ & 75 & 10.2 \\
\hline$>12$ & 33 & 4.5 \\
\hline \multicolumn{3}{|l|}{ Marital Status } \\
\hline Married & 693 & 94.2 \\
\hline Single & 2 & 0.3 \\
\hline Divorced & 35 & 4.8 \\
\hline Widowed & 8 & 0.8 \\
\hline \multicolumn{3}{|l|}{ Occupation of the mother } \\
\hline Government employee & 24 & 3.3 \\
\hline Housewife & 632 & 85.8 \\
\hline Merchant & 35 & 4.8 \\
\hline Farmer & 45 & 6.1 \\
\hline \multicolumn{3}{|l|}{ Family size } \\
\hline$\leq 5$ & 463 & 62.9 \\
\hline$>5$ & 273 & 37.1 \\
\hline \multicolumn{3}{|l|}{ Income } \\
\hline$<1000$ Birr & 423 & 5.3 \\
\hline 1000-1999 Birr & 284 & 25.8 \\
\hline 2000-2999Birr & 21 & 47 \\
\hline > 3000 Birr & 8 & 7 \\
\hline
\end{tabular}

\section{Environmental characteristics}

Out of the 736 respondents interviewed, majority of respondents 562(76.4\%) had less than two rooms per household whose most of living room floor and roof type is mud $725(98.5 \%)$ and corrugated iron $667(90.6 \%)$ respectively. Only $173(23.5 \%)$ of the household have separate house for animals. Most of the households, 395 (82.0\%) used the Pit latrine without slab and only half of the households, 396 (53.8\%) used piped water source for drinking. From sanitary risk assessment survey, majority of the source water, 356 (48.4) and household storage,
314 (42.7) had medium risk of contamination. Moreover, the majority of households 556 (75.5\%) used open field solid waste disposal (Table 2).

\section{Prevalence of diarrhea}

From a total of 736 under five children, 163 under - five children had diarrhea in the 2 week period prior to data collection. Therefore, the 2 week period prevalence of diarrhea was found to be $22.1 \%$ [95\% CI (19.1-25.1)].

\section{Environmental factors associated with diarrheal disease}

In the Univariable binary logistic regression analysis type of roof material, hand washing facility, presence of Latrine facility, ownership of latrine, intermittent water supply, household water treatment, presence of feces around the pit hole, presence of feces around the house compound, risk of contamination of household storage had a p - value less than 0.2 and further analyzed by multivariable binary logistic regression. Finally type of roof material, hand washing facility, presence of Latrine facility, presence of feces around the pit hole, presence of feces around the house compound and risk of contamination of household storage had significant associations with diarrheal morbidity.

Children whose household roof material thatched had two times higher odds of diarrhea than children whose household roof material is corrugated iron [AOR: 1.99, 95\% CI (1.1-3.82)]. The risk of developing diarrhea in children who had hand washing facility was $48 \%$ lower chance [AOR: 0.52, 95\%CI (0.33-0.82)] compared to their counterparts (Table 3).

Children who had no latrine facility had two times higher odds of diarrhea than children who had latrine facility [AOR: 1.65, 95\% CI (1.01-2.72)]. Presence of feces around the pit hole [AOR: 1.65, 95\% CI (1.01-2.72)] and the house compound [AOR: 1.65, 95\% CI (1.01-2.72)] had a significant association with diarrheal disease. The risk of developing diarrheal disease in children who had high sanitary risk of contamination of household storage had five times higher odds of diarrheal disease [AOR: 5.21, 95\% CI (3.01-9.03)] compared to sanitary low risk of contamination of household storage. Moreover, children who had very high sanitary risk of contamination of household storage had strong statistically significant association [AOR: 126.6, 95\% CI (15.5-1036)] with diarrheal disease (Table 3).

\section{Discussion}

The current study determined the prevalence of diarrhea and assessed the environmental factors of diarrhea prevalence among under-five children. The prevalence of diarrhea in the current study was $22.1 \%$. This result is higher than $9.9 \%$ in Sebeta town, Oromiya Region of Ethiopia [8] and $19.6 \%$ in a rural area of Shebedino 
Table 2 Environmental characteristics of respondent household in North Gondar Zone, June, 2016 ( $N=736)$

\begin{tabular}{|c|c|c|c|c|c|}
\hline Variables & Number & Percent (\%) & Variables & Number & Percent (\%) \\
\hline \multicolumn{3}{|l|}{ Type of roof material } & \multicolumn{3}{|l|}{ Household water treatment } \\
\hline Thatched & 69 & 9.4 & Boiling & 13 & 1.8 \\
\hline Corrugated iron & 667 & 90.6 & Filtering & 19 & 2.6 \\
\hline \multicolumn{3}{|l|}{ Type of floor material } & Use of chemicals & 40 & 5.4 \\
\hline Mud & 725 & 98.5 & Allowing water to settle & 12 & 1.6 \\
\hline Cement & 11 & 1.5 & No treatment & 652 & 88.6 \\
\hline \multicolumn{3}{|l|}{ Number of rooms per household } & \multicolumn{3}{|c|}{ Risk of contamination of Household storage } \\
\hline$<=2$ rooms & 562 & 76.4 & Low & 206 & 28 \\
\hline$>2$ rooms & 174 & 23.6 & Medium & 314 & 42.7 \\
\hline \multicolumn{3}{|l|}{ Animals live with human } & High & 198 & 26.9 \\
\hline Yes & 173 & 23.5 & Very high & 18 & 2.4 \\
\hline No & 563 & 76.5 & \multicolumn{3}{|c|}{ Risk of contamination of source water } \\
\hline \multicolumn{3}{|l|}{ Presence of Latrine facility } & Low & 306 & 41.6 \\
\hline Yes & 482 & 65.5 & Medium & 356 & 48.4 \\
\hline No & 254 & 34.5 & High & 74 & 10.1 \\
\hline \multicolumn{3}{|l|}{ Type of Latrine facility $(N=482)$} & \multicolumn{3}{|l|}{ Hand washing facility } \\
\hline Flush/pour flush latrine & 14 & 2.9 & Yes & 392 & 53.3 \\
\hline Ventilated improved pit latrine & 39 & 8.1 & No & 344 & 46.7 \\
\hline Pit latrine with slab & 34 & 7.1 & Place of solid waste disposa & & \\
\hline Pit latrine without slab & 395 & 82 & Pit & 168 & 22.8 \\
\hline \multicolumn{3}{|l|}{ Ownership of latrine $(N=482)$} & Open field & 556 & 75.5 \\
\hline Private & 369 & 76.6 & Burning & 12 & 1.6 \\
\hline
\end{tabular}

Presence of feces around the pit hole $(N=482)$

Yes

No

\section{6}

426

Presence of feces around the house compound

$\begin{array}{ll}\text { Yes } & 112 \\ \text { No } & 624\end{array}$

Source of drinking water

Piped water

Orotected spring and well

Unprotected spring and well

River

Intermittent of Water Supply

Yes

No

Consumption in liter/capita/day

$$
\begin{aligned}
& <20 \text { L/Capita/day } \\
& >=20 \text { L/Capita/day }
\end{aligned}
$$$$
675
$$

Table 2 Environmental characteristics of respondent household in North Gondar Zone, June, 2016 ( $N=736)$ (Continued)

district, southern Ethiopia [13] and it is close with the result $22.5 \%$ of east Ethiopia [9]. However, it is lower than $26.1 \%$ in Hadaleala District, Afar Region of northeast Ethiopia [5], 27.3\% in Jigjiga district, Somali region of Ethiopia [12], 35.6\% in Enderta Woreda, Tigray Region of Ethiopia [6] and 32.6\% in Burundi [14].

In this study, type of roof material, hand washing facility, presence of Latrine facility, presence of feces around the pit hole, presence of feces around the house compound and risk of contamination of household storage had significant associations with diarrheal morbidity.

Children whose household roof material thatched had two times higher odds of diarrhea than children whose household roof material is corrugated iron. This might be due to the poor sanitation of the house in thatched roof compared to the corrugated iron.

The risk of developing diarrhea in children who had hand washing facility was $48 \%$ lower chance compared to their counterparts. This finding is similar with studies done in Sebeta town of Ethiopia [15] and also in Adama District Rural Kebeles [16]. The hand washing facility is important to mothers to easily wash their hands at critical times during the day which is important to reduce fecal-oral transmission of disease. 
Table 3 Environmental factors associated with diarrheal disease prevalence among under five children in North Gondar Zone, June, 2016

\begin{tabular}{|c|c|c|c|c|}
\hline \multirow[t]{2}{*}{ Variable } & \multicolumn{2}{|c|}{ Diarrhea prevalence } & \multirow[t]{2}{*}{ COR $(95 \% \mathrm{Cl})$} & \multirow[t]{2}{*}{ AOR $(95 \% \mathrm{Cl})$} \\
\hline & Yes, n (\%) & No, n (\%) & & \\
\hline \multicolumn{5}{|l|}{ Type of roof material } \\
\hline Thatched & $20(29.0)$ & 49(71.0) & $1.49(0.86-2.59)$ & $1.99(1.1-3.82)^{*}$ \\
\hline Corrugated iron & $143(21.4)$ & $524(78.6)$ & 1.00 & $1: 00$ \\
\hline \multicolumn{5}{|c|}{ Number of rooms in the house } \\
\hline$<=2$ room & $124(22.1)$ & 438(77.9) & $0.98(0.65-1.47)$ & \\
\hline$>2$ room & $39(22.4)$ & 135(77.6) & $1: 00$ & \\
\hline \multicolumn{5}{|l|}{ Hand washing facility } \\
\hline Yes & $63(18.3)$ & $281(81.7)$ & $0.66(0.46-0.93)^{*}$ & $0.52(0.33-0.82)^{*}$ \\
\hline No & $100(25.5)$ & $292(74.5)$ & 1.00 & 1.00 \\
\hline \multicolumn{5}{|c|}{ Animals live with human } \\
\hline Yes & $38(22.0)$ & 135(78.0) & $0.99(0.65-1.49)$ & \\
\hline No & $125(22.2)$ & $438(77.68$ & 1.00 & \\
\hline \multicolumn{5}{|c|}{ Presence of Latrine facility } \\
\hline Yes & $100(20.7)$ & $382(79.3)$ & 1.00 & $1: 00$ \\
\hline No & $63(24.8)$ & $191(75.2)$ & $1.26(0.88-1.81)$ & $1.65(1.01-2.72)^{*}$ \\
\hline \multicolumn{5}{|l|}{ Type of latrine facility } \\
\hline Unimproved & $84(21.3)$ & $311(78.7)$ & $1.20(0.66-2.17)$ & \\
\hline Improved & 16(18.4) & $71(81.6)$ & $1: 00$ & \\
\hline \multicolumn{5}{|l|}{ Ownership of latrine } \\
\hline Private & $83(22.5)$ & $286(77.5)$ & 1.00 & $1: 00$ \\
\hline Shared & $17(15.0)$ & $96(85.0)$ & $0.61(0.34-1.08)$ & $1.09(0.58-2.07)$ \\
\hline \multicolumn{5}{|c|}{ Source of drinking water } \\
\hline Unimproved & $33(22.0)$ & $117(78.0)$ & $0.98(0.64-1.53)$ & \\
\hline Improved & $130(22.2)$ & $456(77.8)$ & 1.00 & \\
\hline \multicolumn{5}{|c|}{ Intermittent water supply } \\
\hline Yes & $114(24.7)$ & $347(75.3)$ & $1.52(1.04-2.20)^{*}$ & $1.23(0.79-1.91)$ \\
\hline No & 49(17.8) & $226(82.2)$ & 1.00 & 1.00 \\
\hline \multicolumn{5}{|c|}{ Water consumption in liter/capita/day } \\
\hline$<20$ L/Capita/day & 153(22.7) & $522(77.3)$ & $0.669(0.332-1.349)$ & \\
\hline$>=20 \mathrm{~L} /$ Capita/day & 10(16.4) & $51(83.6)$ & 1.00 & \\
\hline \multicolumn{5}{|c|}{ Household water treatment } \\
\hline No & $131(20.1)$ & $521(79.9)$ & $2.45(1.51-3.95)$ & $0.67(0.37-1.21)$ \\
\hline Yes & $32(38.1)$ & $52(61.9)$ & 1.00 & 1.00 \\
\hline \multicolumn{5}{|c|}{ Presence of feces around the pit hole } \\
\hline Yes & 22(39.3) & $34(60.7)$ & $1.96(1.07-3.6)^{*}$ & $2.46(1.20-5.04)^{*}$ \\
\hline No & 78(18.3) & $348(81.7)$ & 1.00 & 1.00 \\
\hline \multicolumn{5}{|c|}{ Presence of feces around the house compound } \\
\hline Yes & 48(42.9) & $64(57.1)$ & $3.32(2.17-5.08)^{* *}$ & $2.09(1.24-3.54)^{*}$ \\
\hline No & 115(18.4) & $509(81.6)$ & 1.00 & 1.00 \\
\hline \multicolumn{5}{|c|}{ Methods of solid waste disposal } \\
\hline Pit & $56(33.3)$ & $112(66.7)$ & $80,766(0.00-)$ & \\
\hline Open field & 107(19.2) & $449(80.8)$ & $38,494(0.00-)$ & \\
\hline Burning & $0(0)$ & 12(100) & $1: 00$ & \\
\hline
\end{tabular}


Table 3 Environmental factors associated with diarrheal disease prevalence among under five children in North Gondar Zone, June, 2016 (Continued)

\begin{tabular}{|c|c|c|c|c|}
\hline \multirow[t]{2}{*}{ Variable } & \multicolumn{2}{|c|}{ Diarrhea prevalence } & \multirow[t]{2}{*}{$\operatorname{COR}(95 \% \mathrm{Cl})$} & \multirow[t]{2}{*}{ AOR $(95 \% \mathrm{Cl})$} \\
\hline & $\overline{Y e s, ~ n ~(\%) ~}$ & No, n (\%) & & \\
\hline \multicolumn{5}{|c|}{ Risk of contamination of Household storage } \\
\hline Low & 29(14.1) & 177(85.9) & $1: 00$ & $1: 00$ \\
\hline Medium & $38(12.1)$ & 276(87.9) & $0.84(0.50-1.41)$ & $1.07(0.61-1.89)$ \\
\hline High & 79(39.9) & 119(60.1) & $4.05(2.49-6.58)^{* *}$ & 5.21(3.01-show [?A3B2 show \$9\#?]9.03)** \\
\hline Very high & 17(94.4) & $1(5.6)$ & $103.7(13.3-809.7)^{* *}$ & $\begin{array}{l}126.6(15.5- \\
1036)^{* *}\end{array}$ \\
\hline
\end{tabular}

Risk of contamination of source water

$\begin{array}{llll}\text { Low } & 77(25.2) & 229(74.4) & 1: 00 \\ \text { Medium } & 71(19.9) & 285(80.1) & 0.74(0.51-1.07) \\ \text { High } & 15(20.3) & 59(79.7) & 0.77(0.41-1.41)\end{array}$

* Statistically significant with $p$-value $<0.05,{ }^{* *}$ statistically significant at $p$-value $<0.001$

Children who had no latrine facility had two times higher odds of diarrhea than children who had latrine facility. This finding is in agreement with studies done in West Gojam Ethiopia [17] and in Deresha district, Southern Ethiopia [18]. The presence of latrine increases the chance of its utilization which in turn facilitates the safe disposal of feces. This is one way of decreasing contact between causative organisms of diarrhoeal and the host.

Presence of feces around the pit hole had a significant association with diarrheal disease. This result is comparable with studies done in Nekemte town, western Ethiopia [10] and in Addis Ababa, Ethiopia [19]. Presence of feces around the house compound had a significant association with diarrheal disease. This is due to the fact pathogens in feces disposed in compounds near the house can contaminate the environment and the food eaten by children which leads to diarrheal disease [20-23].

The risk of developing diarrheal disease in children who had high sanitary risk of contamination of household storage had five times higher odds of diarrheal disease compared to sanitary low risk of contamination of household storage. Moreover, children who had very high sanitary risk of contamination of household storage had strong statistically significant association with diarrheal disease. This finding is similar with studies done in Nigeria [24].

The rest variables like type of latrine facility, ownership of latrine, source of drinking water, intermittent water supply, and household water treatment were not significant variables in this study. But, they were significant in the previous studies conducted in different regions of Ethiopia [8, 11]. These discrepancy might be due to the strengthen of Ethiopia's Health Extension Program (HEP) from time to time that has created greater awareness of how to prevent communicable diseases such as malaria, tuberculosis, HIV/AIDS and waterborne disease like diarrhea to the community [25]. Moreover, the discrepancy can be due to difference in seasonal variation.

\section{Conclusion}

In the current study, prevalence of diarrhea found to be high (22.1\%). Type of roof material, hand washing facility, presence of latrine facility, presence of feces around the pit hole, presence of feces around the house compound and risk of contamination of household storage had significant associations with diarrheal morbidity.

\section{Abbreviations}

AOR: Adjusted odd ratio; Cl: Confidence interval; COR: Crude odd ratio; ETB: Ethiopian birr; PPS: Probability proportion to size; WHO: World health organization

\section{Acknowledgements}

The authors would like to thank University of Gondar for its financial support. We are also thankful for study participants, data collectors and supervisors for their devotion and full participation.

\section{Funding}

The authors of this study did not receive funds from any funding organization. However, University of Gondar had covered questionnaire duplication and the per diem for data collector.

\section{Availability of data and materials}

Data will be made available upon requesting the primary author.

\section{Authors' contributions}

AG: participated in the conception and design of the study, data collection and analysis, interpretation of the findings. AT: Participated in the design of the study, data collection, drafting the manuscript and write up, analysis and interpretations of the findings. MG: Participated in the design of the study, interpretations of the findings. TG: Participated in the design of the study, data collection. TG: Participated in the design of the study, data collection. DH: Participated in the design of the study. ZG: Participated in the design of the study. MA: Participated in analysis, interpretations of the findings. All authors read and approved the final manuscript.

\section{Ethics approval and consent to participate}

Ethical clearance was obtained from University of Gondar. After thoroughly discussing the ultimate purpose and method of the study, a written consent was obtained from Institutional Ethical Committee of University of Gondar. Then, community consent was obtained from the respective community leaders. The privacy and confidentiality were maintained during interview. Therefore, only coding was included in the data collection tools. In addition, participants in the study that were not willing to take part in the study had full right to do so. Children that have diarrheal disease were referred to the near health facilities for treatment. 


\section{Consent for publication}

This manuscript does not contain any individual person's data.

\section{Competing interests}

The authors declare that they have no competing interests.

\section{Publisher's Note}

Springer Nature remains neutral with regard to jurisdictional claims in published maps and institutional affiliations.

\section{Author details}

${ }^{1}$ College of Medicine and Health Sciences, Institute of Public Health, Department of Environmental \& Occupational Health \& Safety, University of Gondar, P.O. Box 196, Gondar, Ethiopia. ${ }^{2}$ Department of Ecological and Systematic Zoology, College of Natural and Computational Science, University of Gondar, Gondar, Ethiopia. ${ }^{3}$ Department of Medical Microbiology, Institute of Biomedical Sciences, University of Gondar, Gondar, Ethiopia.

Received: 26 January 2018 Accepted: 12 August 2018

Published online: 16 August 2018

\section{References}

1. Carvajal-Vélez L, Amouzou A, Perin J, Maïga A, Tarekegn H, Akinyemi A, Shiferaw S, Young M, Bryce J, Newby H. Diarrhea management in children under five in sub-Saharan Africa: does the source of care matter? A Countdown analysis. BMC Public Health. 2016;16(1):830

2. Barreto ML, Genser B, Strina A, Assis AMO, Rego RF, Teles CA, Prado MS, Matos SM, Santos DN, dos Santos LA. Effect of city-wide sanitation programme on reduction in rate of childhood diarrhoea in Northeast Brazil: assessment by two cohort studies. Lancet. 2007;370(9599):1622-8.

3. UNICEF/WHO: Diarrhoea:Why children are still dying and what can be done. 2009.

4. Mekasha A, Tesfahun A. Determinants of diarrhoeal diseases: a community based study in urban south western Ethiopia. East Afr Med J. 2003;80(2):77-82.

5. Woldu W, Bitew BD, Gizaw Z. Socioeconomic factors associated with diarrheal diseases among under-five children of the nomadic population in Northeast Ethiopia. Trop Med Health. 2016;44(1):40.

6. Hailemariam B, Abadi M, Gebre Y. Prevalence of diarrhea and associated factors among children under-five years of age in enderta woreda, Tigray, northern Ethiopia, 2014. Int J Ther Appl. 2016;31:32-7.

7. Alelign T, Asegidew W, Abera A. A cross sectional study on the incidence and risk factors of diarrheal illness among children under-five years of age in Debre Berhan town, Ethiopia. J Health Med Econ. 2016;2:2.

8. Mohammeda A, Zungub L. Environmental health factors associated with diarrhoeal diseases among under-five children in the Sebeta town of Ethiopia. South Afr J Infect Dis. 2016;31(4):122-9.

9. Mengistie B, Berhane $Y$, Worku A. Prevalence of diarrhea and associated risk factors among children under-five years of age in eastern Ethiopia: a crosssectional study. Open J Prev Med. 2013;3(07):446.

10. Regassa G, Birke W, Deboch B. Environmental determinants of diarrhea among under-five children in NEKEMTE town, Western Ethiopia. Ethiop J Health Sci. 2008;18(2):39-45.

11. Dearden KA, Schott W, Crookston BT, Humphries DL, Penny ME, Behrman JR Children with access to improved sanitation but not improved water are at lower risk of stunting compared to children without access: a cohort study in Ethiopia, India, Peru, and Vietnam. BMC Public Health. 2017;17(1):110.

12. Hashi A, Kumie A, Gasana J. Prevalence of Diarrhoea and associated factors among under-five children in Jigjiga District, Somali region, eastern Ethiopia. Open J Prev Med. 2016;6(10):233.

13. Alemu Tamiso, Mezgebu Yitayal, Akilew Awoke. Prevalence and Determinants of Childhood Diarrhoea among Graduated Households, in Rural Area of Shebedino District, Southern Ethiopia, 2013. Sci J Public Health. 2014;2(No. 3): 243-251. doi: https://doi.org/10.11648/j.sjph.20140203.28

14. Diouf K, Tabatabai P, Rudolph J, Marx M. Diarrhoea prevalence in children under five years of age in rural Burundi: an assessment of social and behavioural factors at the household level. Glob Health Action. 2014;7:1-9.

15. Mohammed A, Zungu L. Environmental health factors associated with diarrhoeal diseases among under-five children in the Sebeta town of Ethiopia. South Afr J Infect Dis. 2015;31(4):122-9.
16. Regassa W, Lemma S. Assessment of diarrheal disease prevalence and associated risk factors in children of 6-59 months old at Adama District rura Kebeles, eastern Ethiopia, January/2015. Ethiopian Journal of Health Sciences. 2016:26(6):581.

17. Dessalegn M, Kumie A, Tefera W. Predictors of under-five childhood diarrhea: Mecha District, West Gojam, Ethiopia. Ethiop J Health Dev. 2011 25(3):192-200.

18. Godana W, Mengiste B. Environmental factors associated with acute diarrhea among children under five years of age in derashe district, southern Ethiopia. Science Journal of Public Health. 2013;1(3):119-24.

19. Adane M, Mengistie B, Kloos H, Medhin G, Mulat W. Sanitation facilities, hygienic conditions, and prevalence of acute diarrhea among under-five children in slums of Addis Ababa, Ethiopia: baseline survey of a longitudinal study. PLoS One. 2017;12(8):e0182783.

20. Oyemade A, Omokhodion FO, Olawuyi JF, Sridhar MK, Olaseha IO. Environmental and personal hygiene practices: risk factors for diarrhoea among children of Nigerian market women. J Diarrhoeal Dis Res. 1998;16(4): 241-47.

21. Moraes LRS, Cancio JA, Cairncross S, Huttly S. Impact of drainage and sewerage on diarrhoea in poor urban areas in Salvador, Brazil. Trans R Soc Trop Med Hyg. 2003;97(2):153-8.

22. Black RE, Morris SS, Bryce J. Where and why are 10 million children dying every year? Lancet. 2003;361(9376):2226-34.

23. Makoni F, Ndamba J, Mbati P, Manase G. Impact of waste disposal on health of a poor urban community in Zimbambwe. East Afr Med J. 2004; 81(8):422-6.

24. Oloruntoba EO, Folarin TB, Ayede Al. Hygiene and sanitation risk factors of diarrhoeal disease among under-five children in Ibadan, Nigeria. Afr Health Sci. 2014;14(4):1001-11.

25. Banteyerga $\mathrm{H}$. Ethiopia's health extension program: improving health through community involvement. MEDICC Rev. 2011;13(3):46-9.

\section{Ready to submit your research? Choose BMC and benefit from:}

- fast, convenient online submission

- thorough peer review by experienced researchers in your field

- rapid publication on acceptance

- support for research data, including large and complex data types

- gold Open Access which fosters wider collaboration and increased citations

- maximum visibility for your research: over $100 \mathrm{M}$ website views per year

At $\mathrm{BMC}$, research is always in progress.

Learn more biomedcentral.com/submissions 